\title{
Another Hotel Room, Another City, Another Training: Reflections on Co-optation of Feminism by Development
}

Wendy Harcourt, International Institute of Social Studies, Netherlands

This reflection explores questions surrounding the co-optation of feminism by development processes in what could be seen as a process of dilution of feminist demands. In the vignettes that follow, I reflect on one training session in South Asia, held for two weeks in 2014, in order to explore the ambiguities of feminists working inside development. The training also considered the frustrating ways that hegemonic male privilege shapes gender in their work (Fraser 2013). ${ }^{i}$ I was there as a member of a three-person team from my Dutch academic institute to conduct a two-week "refresher" course in gender and sexuality issues to former students now working in South Asia.

Each morning, as my co-trainers and I ate breakfast, we would sit on the hotel rooftop, high above a busy road eating toast and eggs and looking across at the water, the rubbish, and the slums. Around me were young, well-dressed consultants of different nationalities and genders eating while they scanned their iPads, mobile phones and laptops, or held early meetings to discuss evaluations or plan projects. Such a setting demarcated me as participating in a flourishing development industry.

Shortly before 9:00 in the morning, a car would pick us up to go to the training centre. Although the centre was within easy walking distance, the pollution at that time of year made breathing difficult. My physical discomfort at the pollution set out my otherness in a landscape where many thousands had to walk, whatever the pollution level. Once in the training centre we did not leave until the end of the day, and all our tea breaks and lunches were in the centre's canteen.

Inside the room, there was all that was required: whiteboards, a projector for PowerPoint and moveable wooden desks. As in almost all such trainings, the air conditioning was a source of contention for participants: it was too cold with it on; but too hot if it was turned off; and if the windows were open, it was too noisy. One of 
the local trainers commented that she could not survive without air conditioning in her car, in her house, in the trainings. So we stayed cocooned in our cooled meeting space throughout the two weeks.

Our days back and forth between the hotel and the training centre were only interrupted by a field trip to view a successful project, or another evening to listen to NGOs discuss their work, or a visit to a university and tea with an embassy staff member, as well as an afternoon off for shopping and sightseeing. As we were ferried back and forth in traffic that went slower than the many people walking along the unpaved streets, we spoke about the day's work and planned how to run the next. Or we exchanged views on where to buy gifts for family back home. We chatted about other projects, gossiped about people with whom we had worked.

All of the trainers had been to the country before, and we commented on the changes since we had last been there - particularly one person who had been there nearly twenty years earlier. We reminisced about the greener, more authentic past. We expressed surprise and then resignation about the endless shopping streets with the bright lights, the fast food, the terrible traffic, the pollution and the anonymity of it all. We all spoke English and all of us, most of the time, lived in Europe. We were in a bubble of "Aidland" (Mosse 2011), though as progressive feminists we tried to make sense of what we could, conscious of our otherness, while recognizing the familiarity of the modern landscape. The sense of loss of some imagined authentic past was also part of our otherness as we reflected, uncomfortably, on the damage to the culture by modernizing development processes, of which we were a part. According to Arjun Appadurai's "ethnoscape of encounters" $(1996,48)$, there is the sense that western cultures can be diverse and contradictory, whereas "other" cultures should carry something unique and pure and recognizable. Our conversations about such tensions connected us back to other visits in other places, creating our sense of being a part of the wider international community of development experts who were "doing" gender in difficult landscapes of otherness that we could (with support) manoeuvre, while at the same time regretting change. 
Such anonymous details of a development training program are familiar to those engaged in today's streamlined development industry that efficiently produces such activities in modern cities. It is part of the landscape development has delivered. Our concerns and actions, and even emotions about our role, fit well into the ethnography of development that describe how aid policy is carried out, looking at the social life of the projects and organisations and the interactions of the different actors (Ferguson 2015). We could have been development professionals anywhere in modern South Asia, staying in a comfortable hotel room, delivering a training in a well-appointed professional centre. We, like other so-called experts, move from place to place as bids for projects are made, the funds agreed, the training planned, the evaluation sheets completed, the costs monitored and the knowledge given - and the discomfort about our role in the development machinery persists.

There seems nothing noteworthy in my description of the norms of modern development practice, but in considering co-optation of feminist practice it becomes relevant to ask: what difference did it make that we were delivering feminist knowledge on gender and sexuality in a development setting? Did our personal engagement enable us to deliver this knowledge differently in the development setting? What were the histories that led us to deliver such knowledge in a package that brought us together with people from five different countries to do body mapping, debate body politics, and discuss how to do sex education in South Asian schools?

The conditions of possibility for the training were constructed out of multi-layered histories of feminist networks and solidarity movements. The invitation to set up the training itself emerged from several desires and needs. On a personal level there was the desire on the part of the Europeans to come back to the locality, to revisit past places, friends and sights. Two of the trainers had lived for some years in rural areas in the country; one spoke a local language fluently and had maintained close connections to a village. Their professional and personal-political histories were intertwined with the country as solidarity workers and progressive feminists who collaborated during the 1980s campaigning to end population control, to address 
violations and exclusions of women, working together with fledging women's organisations and newly established NGOs. I had also visited in the late 1990s and 2000 s to talk about sexual health and reproductive rights as part of public health campaigns. This landscape was part of the training team's knowledge-formation about the other in our solidarity work as feminists.

The local trainer, a former student, had invited us to come not only to do the training but also to engage in current debates and discussion on body politics in South Asia, and to explore further research possibilities. We were taken to various places and to meet different people. These can be some of the most uncomfortable times of such visits - where the white western scholar/consultant, or in this case the trainer, is awkwardly following the lead of the local person, for agendas that are never completely clear, but are all part of the deal. Such types of connections may appear to blur the power dynamics along class, gender, colonial, or race lines, but at, the same time, everyone is acutely conscious of them.

This crisscrossing of personal and professional connections across Europe and South Asia, over time and enabled by social media, is typical of transnational friendships that make up feminist encounters in development. People meet in various projects, in political campaigns, universities or social movement venues, and then they adapt the engagement, desire and connection into professional encounters. This type of networking is described by Alison Woodward as the "velvet triangle" of informal governance among gender activists in the EU context, as their

demands are taken on board thanks to a patterned dance of needy bureaucrats, dedicated activists and eager academics who are active at national and international levels and frequently linked to each other through informal as well as formal processes. $(2012,145)$

Such patterned dances are required in order to have access to resources made available by the development industry.

The whole training was set up with a shadow set of intentions not explicitly set out in the proposal. The official project aim was to deliver and exchange up-to-date 
knowledge on sexuality and gender and to build a network of feminists already engaged in development practice. The unstated shadow intention was the aim to maintain a sense of connection and belonging amongst different generations, bringing together the teachers and former students of a development institution to meet again, consolidate friendships and support each other in their different jobs in NGOs, community-based organisations, governments and research institutions. In this sense, it blended feminist desires for connection and networking into a sense of belonging to a community of feminists working in transnational development processes. It reconfirmed past friendships and ties to the European institution, creating the possibilities for future connections and, as a certificate course, a further professional line to add to the $\mathrm{CV}$ for both the trainers and participants. The enjoyment of the event included the renewal of friendships and connections, the feminist networking and support of people's work in delivering gender and sex education. This enjoyment sat uncomfortably with the concerns of co-optation into the development industry and with the evident differences of the privilege. These differences were not only in terms of race and geography but also in terms of access to certain forms of "sellable" knowledge and social and economic resources among the trainers and the participants.

In this story, there are many uncomfortable points and contradictions with ideals. But there is also a desire, and even a need to act in solidarity without really knowing culturally and politically how to be. There is the performance of being the gender expert in a public context where I find a strange shadowy version of feminism haunting me. These experiences and feelings are shared across the many other meetings I attended in South Asia during the 2000s. On this particular visit, I was unexpectedly invited to speak at a university. I became very aware of the need to dress appropriately. I checked with the local organiser about what would suit, the jeans I had with me would not do for the occasion. I therefore went out to purchase a glamorous dress from a local outlet, one that I would probably not wear in a European setting. The issue of what clothes to wear, how to behave, what to look like as feminists, as foreigners, and how to use clothes to position ourselves in places other than our own is difficult. "The personal is political" is also embodied place-based 
knowledge, and we rely on being given clues by those who invite us, whether we are others from Europe in South Asia, or others from South Asia in Europe. The wearing of certain clothes to signal respect, education, age and gender is a highly conscious feminist act. I see this feminist awareness of how to appear and behave strategically as part of body politics.

In analysing this story in relation to body and appearance, the question of co-optation of feminism extends to how we perform in such public events. What does a dress say about feminism in those performances of development? The different attires were signalling various messages of what it is to be feminist to an elite audience that understood doing gender in order to get students to think differently about body politics, or to demonstrate that business elites can also be feminists and challenge male economic and social privilege. As highly educated professional women we were part of the elite NGO and business world that make up the Aidland community, with the economic resources to buy the necessary clothes, and to speak to a liberal notion of feminist choice and desire as part of our own personal empowerment. Such a notion of empowerment does not unsettle economic privilege that allows the choices to be made.

The issue of funding was also not on the agenda of the training. Yet, it remained very much part of the event, alongside decisions about who to invite, how to appear, and what to do. Engagement with funders was key to the success of the training in order to promote the local host institution, to reassure them that donor money had been well spent and would create possibilities for further events. These polite visits to embassies and government departments are not minor asides; the host country institute, in order to survive in the development industry, needed to build its political positioning in a heavily competitive scene to secure funds and prestige.

The question is, how much does this behaviour differs from any other business dealing? The use of personal connections, inside knowledge, and people negotiating and pushing the boundaries of rules are all commonplace in the business world. Such political savvy is part of social movement knowledge as well, even if the rules are 
normally less bureaucratic. Woodward (2012) looks at this informal governance network as strategic and a highly successful way to access resources.

In opening up these processes to scrutiny, it is important to recognize how power is operating at different levels. Feminists need to be vigilant, not by denying the feminist process of engagement in development, but by recognizing how feminist strategies can be achieved. It is important to consider how to work the change from within, fully aware of the power dynamics and their role and responsibilities.

As Sara Ahmed comments,

those who straddle academic lives and employ feminist praxis within communities outside of the hallowed halls, often are positioned to act as intermediaries betwixt and between, breaking the age binaries of formal and informal education/knowledge production, and have a great burden in re-positioning and reconciling these multiple spaces. (Ahmed quoted in Carty and Mohanty 2015, 88)

The awkwardness of the training in its air conditioned bubble remains. It was not an event that directly challenged political and economic practices, though it negotiated these challenges around the edges. I see these training sessions as reflecting the realities of feminists in the development world who "tread the line between pessimism and hope, between failures and corruptions of the development industry and the promise that it can really reach the people it aims to reach" (McKinnon 2011, 2).

Wendy Harcourt International Institute of Social Studies, Erasmus University, Kortenaerkade 12 2518AX The Hague, Netherlands Harcourt@iss.nI

\section{Notes on contributor}

Wendy Harcourt is Associate Professor and Research Programme Leader for the Civic Innovation Research Programme at the ISS of Erasmus University. She has edited 12 
books and her monograph, Body Politics in Development: Critical Debates in Gender and Development (Zed Books, 2009), which received the 2010 Feminist and Women's Studies Association Prize.

\section{References}

Appadurai, A. 1996. Modernity at Large: Cultural Dimensions of Globalization. Minnesota: Public Planet Books.

Carty, L. and C.T. Mohanty. 2015. "Mapping Transnational Feminist Engagements." In OUP Handbook of Transnational Feminist Movements, edited by R. Baksh and W. Harcourt, 82-115. Oxford: Oxford University Press.

De Jong, S. 2009. "Intersections of Aid: Women NGO workers' reflections on their work practices." CSSGJ Working Paper Series, University of Nottingham, Centre for the Study of Social and Global Justice. Accessed November 172016. https://www.nottingham.ac.uk/cssgi/documents/working-papers/wp010.pdf

Ferguson, L. 2015. “'This is Our Gender Person': The Messy Business of Working as a Gender Expert in International Development." International Feminist Journal of Politics 17(3): 380-397.

Fraser, N. 2013. Fortunes of Feminism: From State-Managed Capitalism to Neoliberal Crisis. New York: Verso Books.

McKinnon, K. 2011. Development Professionals in Northern Thailand. Singapore: National University of Singapore Press.

Mosse D, ed. 2011. Adventures in Aidland: The Anthropology of Professionals in International Development. New York: Berghahn.

Woodward, A. 2012. "Building Velvet Triangles: Gender and Informal Governance." In Vesalius College: 25 Years of Academic Excellence in Teaching and Research, edited by W.L. Chew and B. Mosselmans, 145-170. Brussels: VUB Press.

\footnotetext{
${ }^{i}$ The vignettes do not make explicit the country or exact place of encounter due to ethical concerns over the privacy of the individuals involved.
} 